\title{
Pengaruh Berbagai Komposisi Media Tanam Hidroponik Sistem DFT pada Pertumbuhan dan Hasil Tanaman Selada (Lactuca sativa L.)
}

\section{(The Effects of Various Hydroponic Planting Media Composition in DFT Systems on the Growth and Yield of Lettuce (Lactuca sativa L.))}

\author{
Nur Hafizah ${ }^{1)}$, Farida Adriani $^{2)}$ \& Muhammad Luthfi ${ }^{3)}$ \\ Program Studi Agroteknologi STIPER Amuntai \\ 1)fifi_bjm@yahoo.co.id \\ 2)adrianifr9@gmail.com \\ ${ }^{3)}$ muhammadluthfi810@gmail.com
}

\begin{abstract}
ABSTRAK
Selada adalah jenis sayuran berdaun hijau yang memiliki banyak manfaat dan sumber vitamin yang baik. Hidroponik DFT merupakan budidaya tanaman tanpa menggunakan tanah. Cocopeat dan hidroton adalah media tanam hidroponik. Penelitian ini bertujuan untuk (i) mengetahui pengaruh berbagai komposisi media tanam hidroponik sistem DFT pada pertumbuhan dan hasil tanaman selada (ii) mendapatkan komposisi media tanam hidroponik sistem DFT terbaik pada pertumbuhan dan hasil tanaman selada. Penelitian ini dilaksanakan di Desa Rica Kecamatan Paringin Kabupaten Balangan dari bulan Februari sampai bulan April 2019. Penelitian ini menggunakan Rancangan Acak Kelompok (RAK) faktor tunggal. Faktor yang diamati adalah komposisi media tanam hidroponik sistem DFT $(m)$ sebanyak 5 taraf yang terdiri darim $m_{1}=100 \%$ cocopeat $: 0 \%$ hidroton (100 g cocopeat : $0 \mathrm{~g}$ hidroton), $m_{2}=0 \%$ cocopeat $: 100 \%$ hidroton ( $0 \mathrm{~g}$ cocopeat $: 100 \mathrm{~g}$ hidroton), $\mathrm{m}_{3}=50 \%$ cocopeat $: 50 \%$ hidroton $(50 \mathrm{~g}$ cocopeat $: 50$ $g$ hidroton), $m_{4}=75 \%$ cocopeat $: 25 \%$ hidroton (75 g cocopeat $: 25 \mathrm{~g}$ hidroton), $m_{5}=25 \%$ cocopeat : $75 \%$ hidroton (25 g cocopeat : $75 \mathrm{~g}$ hidroton). Hasil penelitian menunjukan bahwa perlakuan komposisi media tanam hidroponik berpengaruh sangat nyata terhadap tinggi tanaman 14,21,28 dan 35 HST, berpengaruh sangat nyata terahdap jumlah daun 7,21,28 dan 35 HST, berpengaruh sangat nyata terhadap berat basah tanaman. Perlakuan terbaik terdapat pada perlakuan $m_{5}=25 \%$ cocopeat $: 75 \%$ hidroton $(25$ g cocopeat : 75 g hidroton).
\end{abstract}

Kata kunci: Selada, cocopeat, hidroton, hidroponik DFT.

\section{ABSTRACT}

Lettuce is a type of green leafy vegetable that has many benefits and a good source of vitamins. DFT hydroponics is plant cultivation without using soil. Cocopeat and hydroton are hydroponic growing media. This study aims to (i)determine the effect of various compositions of the DFT hydroponic growing media on growth and yield of lettuce (ii) obtaining the best composition of the DFT hydroponic planting media on growth and yield of lettuce. This study was conducted in Rica Village, Paringin District, Balangan Regency from February to April 2019. This study used a Randomized Design Group (RDG)single factor. The factors observed were the composition of the hydroponic planting media of the DFT system $(m)$ by as much as 5 degrees of consisting of $m_{1}=100 \%$ cocopeat: $0 \%$ hydroton (100 g cocopeat: 0 g hydroton), $m_{2}$ $=0 \%$ cocopeat: $100 \%$ hydroton (0 g cocopeat: $100 \mathrm{~g}$ hydroton), $m_{3}=50 \%$ cocopeat: $50 \%$ hydroton (50 $g$ cocopeat: $50 \mathrm{~g}$ hydroton), $m_{4}=75 \%$ cocopeat: $25 \%$ hydroton ( $75 \mathrm{~g}$ cocopeat: $25 \mathrm{~g}$ hydroton), $m_{5}=25 \%$ cocopeat: $75 \%$ hydroton (25 g cocopeat: $75 \mathrm{~g}$ hydroton). The results showed that the treatment of the composition of the hydroponic growing media had a very significant effect on plant height 14,21,28 and 35 HST, the effect was very significant on the number of leaves 7,21,28 and 35 HST, significantly affected the wet weight of the plant. The best treatment is obtained at $m_{5}=25 \%$ cocopeat: $75 \%$ hydroton $(25 \mathrm{~g}$ cocopeat: 75 g hydroton).

Keywords: Lettuce, cocopeat, hydroton, hydroponic DFT.

\section{PENDAHULUAN}

Tanaman selada adalah sayuran yang mempunyai nilai ekonomis tinggi, pengembangan budidaya selada mempunyai prospek yang bagus karena dapat meningkatkan pendapatan petani dan sumber gizi masyarakat (Nugroho et. al., 
2017).Perkembangan tanaman selada di Kabupaten Balangan masih terbilang minim karena selada belum begitu familiar dikalangan masyarakat dan belum ada masyarakat yang membudidayakan tanaman selada baik secara konvensional maupun secara hidroponik.

Semakin tingginya alih fungsi lahan pertanian menjadi perumahan, pemukimandan sektor industri membuat usahapertanian konvensional terhambat. Hidroponik merupakan solusi yang tepat untuk tetap bisa melakukan budidaya tanaman, hidroponik merupakan metode budidaya tanaman yang menggunakan media tanam selain tanah yang tidak membutuhkan lahan yang besar dengan memanfaatkan lahan yang sempit (Binaraesa, et. al., 2016).

Hidroponik Sistem Deep Flow Technique (DFT) sangat cocok diterapkan di daerah yang sering mengalami pemadaman listrik dan menjadi solusi untuk menghemat biaya pemakaian listrik. Hidroponik sistem DFT umumnya digunakan untuk menanam tanaman sayuran daun, baik yang memiliki pertumbuhan meninggi seperti kangkung maupun yang melebar seperti selada (Nurdin, 2017).

Media tanam ialah salah satu hal utama yang harus diperhatikan dalam budidaya dengan sistem hidroponik, karena media tanam yang berperan menyimpan nutrisi dan menyangga tanaman. Jenis media tanam yang dapat diguakan untuk budidaya dengan sistem hidroponik dapat terbuat dari bahan anorganik dan organik dengan berbagai jenis media tanam (Maitimu dan Suryanto, 2018).

Cocopeat (sabut kelapa) merupakan media tanam hidroponik yang terbuat dari sabut kelapa tua yang telah dihaluskan menjadi bubuk-bubuk seperti pasir, cocopeat dapat menjadi media tanam hidroponik baik pada saat penyemaian atau pembesaran (Nurdin, 2017).

Hidroton merupakan media tanam hidroponik yang berbentuk bulat, dalam bulatan-bulatan terdapat pori-pori yang dapat menyerap air sehingga dapat menjaga ketersediaan nutrisi untuk tanaman hidroponik.

Pembuatan hidroton menggunakan tanah liat karena merupakan jenis tanah yang bertekstur halus dan lengket atau berlumpur (Siregar, et. al., 2017).

Penelitian ini bertujuan untuk mengetahui pengaruh, (i) komposisi media tanam hidroponik sistem DFT, (ii) mendapatkan komposisi media tanam hidroponik sistem DFT terbaik.

\section{METODE PENELITIAN}

Penelitianini dilaksanakan di Desa Rica Kecamatan Paringin Kabupaten Balangan Provinsi Kalimantan Selatan, pada bulan Februari sampai bulan April 2019.Menggunakan Rancangan Acak Kelompok (RAK) dengan faktor tunggal, pengelompokan berdasarkan tinggi bibit. Faktor yang diteliti adalah komposisi media cocopeat dengan hidroton $(\mathrm{m})$ sebanyak 5 taraf yaitu $: \mathrm{m}_{1}=100 \%$ cocopeat : $0 \%$ hidroton $(100 \mathrm{~g}$ cocopeat $: 0 \mathrm{~g}$ hidroton $) \mathrm{m}_{2}=$ $0 \%$ cocopeat : $100 \%$ hidroton (0g cocopeat : $100 \mathrm{~g}$ hidroton $) \mathrm{m}_{3}=50 \%$ cocopeat $: 50 \%$ hidroton $\left(50 \mathrm{~g}\right.$ cocopeat $: 50 \mathrm{~g}$ hidroton), $\mathrm{m}_{4}=$ $75 \%$ cocopeat : $25 \%$ hidroton $(75 \mathrm{~g}$ cocopeat $: 25 \mathrm{~g}$ hidroton) $\mathrm{m}_{5}=25 \%$ cocopeat $: 75 \%$ hidroton (25g cocopeat : $75 \mathrm{~g}$ hidroton). Dengan demikian terdapat 25 satuan percobaan, setiap satuan percobaan terdiri dari 6 tanaman dengan 4 tanaman sebagai sampel sehingga terdapat 150 tanaman.Variabel pengamatan yang diamati adalah : tinggi tanaman, jumlah daun dan berat basah tanaman.

\section{HASIL DAN PEMBAHASAN}

\section{Tinggi Tanaman}

Hasil analisis ragam peubah yang diamati menunjukkan bahwa perlakuan komposisi media tanam hidroponik tidak berpengaruh terhadap tinggi tanaman umur 7 HST tetapi berpengaruh sangat nyata terhadap tinggi tanaman selada pada umur 14, 21, 28 dan 35 HST. Hasil uji beda ratarata tinggi tanaman dapat dilihat pada tabel berikut ini. 
64

Nur Hafizah, Farida Adriani \& Muhammad Luthfi. Pengaruh komposisi berbagai media tanam...

Tabel 1. Hasil uji beda rata-rata tinggi tanaman selada pada berbagai komposisi media tanam hidroponik.

\begin{tabular}{ccccc}
\hline \multirow{2}{*}{ Perlakuan } & \multicolumn{4}{c}{ Rata-Rata Tinggi Tanaman $(\mathrm{cm})$} \\
\cline { 2 - 5 } & $14 \mathrm{HST}$ & $21 \mathrm{HST}$ & $28 \mathrm{HST}$ & $35 \mathrm{HST}$ \\
\hline $\mathrm{m}_{1}$ & $6,19^{\mathrm{b}}$ & $10,37^{\mathrm{b}}$ & $11,99^{\mathrm{b}}$ & $13,86^{\mathrm{b}}$ \\
$\mathrm{m}_{2}$ & $4,56^{\mathrm{a}}$ & $7,68^{\mathrm{a}}$ & $9,23^{\mathrm{a}}$ & $10,07^{\mathrm{a}}$ \\
$\mathrm{m}_{3}$ & $6,55^{\mathrm{b}}$ & $10,63^{\mathrm{b}}$ & $12,24^{\mathrm{c}}$ & $14,00^{\mathrm{c}}$ \\
$\mathrm{m}_{4}$ & $6,51^{\mathrm{b}}$ & $10,56^{\mathrm{b}}$ & $12,02^{\mathrm{c}}$ & $13,95^{\mathrm{b}}$ \\
$\mathrm{m}_{5}$ & $7,80^{\mathrm{c}}$ & $11,46^{\mathrm{c}}$ & $13,13^{\mathrm{d}}$ & $15,18^{\mathrm{d}}$ \\
\hline
\end{tabular}

Keterangan : Angka yang diikuti oleh huruf yang sama pada kolom yang sama menunjukkan perlakuan tersebut tidak berbeda berdasarkan Uji DMRT pada taraf nyata 5\%.

Dari tabel di atas dapat dilihat bahwa pada umur 14 HST perlakuan $\mathrm{m}_{5}$ menunjukan rata-rata tinggi tanaman tertinggi yaitu 7,80 $\mathrm{cm}$ yang berbeda dengan perlakuan $\mathrm{m}_{1}, \mathrm{~m}_{2}$, $\mathrm{m}_{3}$ dan $\mathrm{m}_{4}$. Sedangkan pada umur 21,28 dan 35 HST, perlakuan m 5 masih menunjukan rata-rata tinggi tanaman tertinggi yaitu, 11,46 $\mathrm{cm}, 13,13 \mathrm{~cm}$ dan $15,18 \mathrm{~cm}$ namun tidak berbeda dengan perlakuan $\mathrm{m}_{1}, \mathrm{~m}_{2}, \mathrm{~m}_{3}$ dan $\mathrm{m}_{4}$.

\section{Jumlah Daun}

Hasil analisis ragam peubah yang diamati menunjukkan bahwa perlakuan komposisi media tanam hidroponikberpengaruh sangat nyata terhadap jumlah daun tanaman selada pada umur 7, 21, 28 dan 35 HST. Berpengaruh nyata terhadap jumlah daun umur 14 HST. Hasil uji beda rata-rata jumlah daun dapat dilihat pada tabel berikut ini.

Tabel 2. Hasil uji beda rata-rata jumlah daun tanaman selada pada berbagai komposisi media tanam hidroponik.

\begin{tabular}{cccccc}
\hline \multirow{2}{*}{ Perlakuan } & \multicolumn{5}{c}{ Rata-Rata Jumlah Daun (helai) } \\
\cline { 2 - 6 } & 7 HST & 14 HST & 21 HST & 28 HST & 35 HST \\
\hline $\mathrm{m}_{1}$ & $3,5^{\mathrm{a}}$ & $5,15^{\mathrm{b}}$ & $6,1^{\mathrm{b}}$ & $7,1^{\mathrm{b}}$ & $9,75^{\mathrm{b}}$ \\
$\mathrm{m}_{2}$ & $3,35^{\mathrm{a}}$ & $4,05^{\mathrm{a}}$ & $4,25^{\mathrm{a}}$ & $5,2^{\mathrm{a}}$ & $6,25^{\mathrm{a}}$ \\
$\mathrm{m}_{3}$ & $4,65^{\mathrm{b}}$ & $5,6^{\mathrm{b}}$ & $6,25^{\mathrm{b}}$ & $7,35^{\mathrm{b}}$ & $11,3^{\mathrm{c}}$ \\
$\mathrm{m}_{4}$ & $4,6^{\mathrm{b}}$ & $5,45^{\mathrm{b}}$ & $6,15^{\mathrm{b}}$ & $7,2^{\mathrm{b}}$ & $9,75^{\mathrm{b}}$ \\
$\mathrm{m}_{5}$ & $4,6^{\mathrm{b}}$ & $5,7^{\mathrm{b}}$ & $7,05^{\mathrm{c}}$ & $8,35^{\mathrm{c}}$ & $13,35^{\mathrm{d}}$ \\
\hline
\end{tabular}

Keterangan : Angka yang diikuti oleh huruf yang sama pada kolom yang sama menunjukkan perlakuan tersebut tidak berbeda berdasarkan Uji DMRT pada taraf nyata 5\%.

Dari tabel di atas dapat dilihat bahwa pada umur 7 HST perlakuan $m_{3}$ menunjukan rata-rata jumlah daun tanaman terbanyak yaitu 4,65 helai tetapi tidak berbeda dengan perlakuan $\mathrm{m}_{4} \mathrm{dan} \mathrm{m}_{5}$ berbeda nyata dengan $\mathrm{m}_{1}$ dan $\mathrm{m}_{2}$. Pada umur 14 HST perlakuan $\mathrm{m}_{5}$ menunjukan rata-rata jumlah daun tanaman terbanyak yaitu 5,7 helai tetapi tidak berbeda dengan perlakuan $\mathrm{m}_{4}$ dan $\mathrm{m}_{5}$ berbeda nyata dengan $\mathrm{m}_{2}$. Pada umur 21,28 dan 35 HST perlakuan $m_{5}$ menunjukan rata-rata jumlah daun tanaman terbanyak yaitu7,05 helai, 8,35 helai dan 13,35 yang berbeda dengan perlakuan $\mathrm{m}_{1}, \mathrm{~m}_{2} \mathrm{~m}_{3}$ dan $\mathrm{m}_{4}$.

\section{Berat Basah Tanaman}

Hasil analisis ragam peubah yang diamati menunjukkan bahwa perlakuan komposisi media tanam hidroponikberpengaruh sangat nyata terhadap berat basah tanaman selada. Hasil uji beda rata-rata berat basah tanaman dapat dilihat pada tabel berikut ini. 
Tabel 3. Hasil uji beda rata-rata berat basah tanaman selada pada berbagai komposisi media tanam hidroponik.

\begin{tabular}{cc}
\hline Perlakuan & Berat Basah Tanaman $(\mathrm{g})$ \\
\hline $\mathrm{m}_{1}$ & $28,3^{\mathrm{b}}$ \\
$\mathrm{m}_{2}$ & $4,35^{\mathrm{a}}$ \\
$\mathrm{m}_{3}$ & $36,6^{\mathrm{c}}$ \\
$\mathrm{m}_{4}$ & $29,05^{\mathrm{b}}$ \\
$\mathrm{m}_{5}$ & $44,85^{\mathrm{d}}$ \\
\hline
\end{tabular}

Keterangan: Angka yang diikuti oleh huruf yang sama pada kolom yang sama menunjukkan perlakuan tersebut tidak berbeda berdasarkan Uji DMRT pada taraf nyata 5\%.

Dari tabel di atas dapat dilihat bahwa pada perlakuan $\mathrm{m}_{5}$ menunjukan rata-rata berat basah tanaman terberat yaitu $44.85 \mathrm{~g}$ yang berbeda dengan perlakuan $\mathrm{m}_{1}, \mathrm{~m}_{2}, \mathrm{~m}_{3}$ dan $\mathrm{m}_{4}$.

\section{Pembahasan}

Berdasarkan hasil analisis ragampeubah yang diamati menunjukkan bahwa perlakuan komposisi media tanam hidroponiktidak berpengaruh terhadap tinggi tanaman umur 7HST tetapi,berpengaruh sangat nyata terhadap tinggi tanaman selada,pada umur 14, 21, 28 dan 35 HST, berpengaruh sangat nyata terhadap jumlah daunpada umur 7, 21, 28 dan 35 HST dan berpengaruh nyata terhadap jumlah daun umur 14 HST serta berpengaruh sangat nyata terhadapberat basah tanaman selada. Hal ini diduga karena,tanaman selada memiliki batang yang bersifat roset dengan susunan daun yang melingkar rapat sehingga pada umur 7 HST batangnya masih pendek. Hal ini sesuai dengan pernyataan Rendy (2012), yang menyatakan bahwa batang (roset) memiliki batang yang pendek sehingga semua daunnya seakan-akan keluar dari bagian atas akarnya dan tersusun rapat satu sama lain seperti tanaman kubis, selada dan brokoli.

Berpengaruh sangat nyata terhadap tinggi tanaman seladapada umur 14, 21, 28 dan 35 HST, berpengaruh sangat nyata terhadap jumlah daunpada umur 7, 21, 28 dan 35 HST dan berpengaruh nyata terhadap jumlah daun umur 14 HST. Hal ini diduga karena tanaman selada mendapatkan media tanam yang baik untuk pertumbuhan tinggi tanaman dan jumlah daun tanaman selada, komposisi media tanam cocopeat dan hidroton merupakan media tanam yang baik untuk pertumbuhan tanaman selada karena dapat menghasilkan media tanam yang mampu menyimpan air nutrisi lebih lama dan mudah ditembus akar serta memiliki sirkulasi udara yang baik bagi akar tanaman, karena media tanam cocopeat dan hidroton memiliki kelebihan masing-masing yang baik untuk dikomposisikan. Menurut Artha (2014), cocopeat adalah media tanam ramah lingkungan karena berasal dari bahan organik yang aman, keunggulan media tanamcocopeat adalah memiliki daya serap air tinggi yang baik dalam menyimpan air dengan $\mathrm{pH}$ netral, dan cocopeat juga mengandung unsur hara dari alam yang dapat membantu pertumbuhan tanaman.

Berpengaruh sangat nyata terhadap tinggi tanaman seladapada umur 14, 21, 28 dan 35 HST, berpengaruh sangat nyata terhadap jumlah daunpada umur 7, 21, 28 dan 35 HST dan berpengaruh nyata terhadap jumlah daun umur 14 HST. Hal ini diduga karena tanaman selada mendapatkan media tanam yang baik untuk pertumbuhan tinggi tanaman dan jumlah daun tanaman selada, komposisi media tanam cocopeat dan hidroton merupakan media tanam yang baik untuk pertumbuhan tanaman selada karena dapat menghasilkan media tanam yang mampu menyimpan air nutrisi lebih lama dan mudah ditembus akar serta memiliki sirkulasi udara yang baik bagi akar tanaman, karena media tanam cocopeat dan hidroton memiliki kelebihan masing-masing yang baik untuk dikomposisikan. Menurut Artha (2014),cocopeat adalah media tanam ramah lingkungan karena berasal dari bahan organik yang aman, keunggulan media tanam cocopeat adalah memiliki daya serap air 
tinggi yang baik dalam menyimpan air dengan $\mathrm{pH}$ netral, dan cocopeat juga mengandung unsur hara dari alam yang dapat membantu pertumbuhan tanaman.

Perlakuan berpengaruh sangat nyata terhadap berat basah tanaman selada. Hal ini diduga tergantung pada tinggi tanaman dan jumlah daun tanaman selada karena berat basah tanaman selada sesuai dengan tinggi tanaman dan jumlah daunnya.

Berdasarkan hasil Uji DMRT pada taraf nyata $5 \%$ didapat bahwa perlakuan $\mathrm{m}_{5}$ (Cocopeat 25\% : Hidroton 75\%) merupakan perlakuan terbaik. Hal ini di duga karena dengan cocopeat yang lebih sedikit dan hidroton yang lebih banyak akan mempermudah akar untuk menembus media tanam karena dengan cocopeat $25 \%$ sudah mampu untuk menyimpan air nutrisi bagi pertumbuhan tanaman dan dengan hidroton $75 \%$ akan mempermudah akar untuk tumbuh dengan baik karena diantara ruang antar bulatan-bulatan hidroton memiliki celah yang mudah ditembus akar sehingga akar tanaman lebih cepat sampai ke aliran nutrisi pada pipa hidroponikdibandingkan dengan perlakuan media tanam lain. Hal ini sesuai dengan pernyataan Sugeng (2016), yang menyatakan setiap jenis tanaman memerlukan karakteristik dan sifat media tanam yang berbeda, seperti tanaman buah memerlukan media tanam yang solid agar bisa menopang pertumbuhan tanaman yang relatif lebih besar, sementara jenis tanaman sayuran memerlukan media tanam yang baik seperti gembur, mampu menyimpan unsur hara bagi tanaman dan mudah ditembus akar.

Media tanam berperan dalam menentukan baik atau buruknya pertumbuhan tanaman yang mempengaruhi hasil produktivitas tanaman tersebut, syarat media tanam hidroponik yang baik adalah mampu menyimpan air nutrisi yang cukup untuk pertumbuhan tanaman, mempunyai drainase dan aerasi yang baik, mudah ditembus akar dan memiliki pH netral (Rifqi, 2017).

\section{KESIMPULAN}

Komposisi media tanam hidroponik sistem DFT tidak berpengaruh pada tinggi tanaman umur 7 HST, tetapi berpengaruh sangat nyata pada umur 14, 21, 28 dan 35 HST, berpengaruh nyata pada jumlah daun umur 14 HST dan berpengaruh sangat nyata pada umur 7, 21, 28 dan 35 HST serta berpengaruh sangat nyata pada berat basah tanaman. Didapatkan komposisi media tanam hidroponik sistem DFT terbaik pada $\mathrm{m}_{5}$ (cocopeat $25 \mathrm{~g}$ dan hidroton $75 \mathrm{~g}$ ) untuk pertumbuhan dan hasil tanaman selada.

\section{UCAPAN TERIMAKASIH}

Ucapan terimakasih kepada LPPM Sekolah Tinggi Ilmu Pertanian Amuntai atas pembiayaan penelitian ini melalui Hibah Penelitian Tahun 2019 dengan kontrak Nomor : 04/LPPM-STIPER AMT/KP/VI/ 2019 tanggal 15 Juni 2019.

\section{DAFTAR PUSTAKA}

Artha, T. (2014). Interaksi pertumbuhan antara shorea selanica dan ganetum gnemon dalam media tanam dengan konsentrasi cocopeat yang berbeda. Skripsi. Fakultas Kehutanan Institut Pertanian. Bogor.

Binaraesa, N. N. P. C., Sutan, S. M., dan Ahmad, A. M. (2016). Nilai Ec (Electro conductivity) berdasarkan umur tanaman selada daun hijau (Lactuca sativa L.) dengan sistem hidroponikNFT (Nutrient FilmTechnique). Jurnal Keteknikan Pertanian Tropis dan Biosistem, 4 (1), 65-74.

Maitimu, D. K. dan Suryanto, A. (2018). Pengaruh media tanam dan konsentrasi AB Mix pada tanaman kubis bunga (Brassica oleraceae var botrytis L.) sistem hidroponik substrat. Jurnal Produksi Tanaman 6(4), 516-523.

Nugroho, D. B., Maghfoer, M. D., dan Herlina, N. (2017). Pertumbuhan dan hasil tanaman selada (Lactuca sativa L.) akibat pemberian biourin sapi dan kascing. Jurnal Produksi Tanaman, 5(4), 600-607. 
Nurdin, SQ. (2017). Mempercepat Panen Sayuran Hidroponik. PT Agromedia Pustaka. Jakarta.

Rendy. (2012). Pengertian Batang (Caulis). https://biologirendy.blogspot.com. Diakses pada tanggal 27 Juli 2019.

Rifqi. (2017). Syarat Media Tanam Hidroponik yang Baik Agar Tanaman Subur. http://ilmubudidaya.com. Diakses pada tanggal 7 Juli 2019.
Siregar, K., Devianti., dan Munawar, I. A. A. (2017). Pengembangan produk tanah liat melalui pembuatan hidroton sebagai media tanam hidroponik berwawasan lingkungan dan kesinambungan. Skripsi. Fakultas Pertanian Universitas Syiah Kuala. Banda Aceh.

Sugeng. (2016). Cara Mudah Membuat Media Tanam Sayuran dalam Polybag. https://ayo-nambahilmu.blogspot.com. Diakses pada tanggal 28 Juli 2019. 